\title{
Study on Design of Concrete Box Girder of A Railway Swivel Cable-Stayed Bridge
}

\author{
Yang Liu ${ }^{1}$,Tenghui Ding ${ }^{1}$, Qinyun $\mathrm{Xie}^{2}$, Guangli $\mathrm{Xu}^{3}$,Chao $\mathrm{Li}^{3}$ \\ ${ }^{1}$ School of Architecture and Planning, Yunnan University, Kunming 650091, China \\ 2 Yunnan Dazhu Technology Co., Ltd, Kunming 650030, China \\ ${ }^{3}$ Yunnan Kunchu expressway investment and Development Co., Ltd, Kunming 650030, China
}

\begin{abstract}
A swivel cable-stayed bridge over the existing railway is a span across the existing railway. The recommended scheme for the main bridge is $(128+388+128) \mathrm{m}$ steel mixed composite beam swivel diagonal pull bridge with span. The cables of the diagonal pull bridge are arranged according to the fanshaped central double cable plane, taking into account the mechanical performance and aesthetics. The bridge structure adopts semi floating system. The concrete swivel diagonal pull bridge is adopted in the comparison scheme. The design of the bridge is three spans and $(138+268+138) \mathrm{m}$ prestressed concrete box girder is adopted. The cables are arranged according to the central double cable plane, and the bridge composition adopts the consolidation system. Considering the needs of bridge operation and maintenance in the later stage of the bridge, when the dead weight of concrete diagonal pull bridge is within the ideal range, the concrete swivel diagonal pull bridge can be preferred. In order to calculate the dead weight of the selected bridge, the author uses the finite element software to model the whole bridge and calculate the weight of the bridge. The results show that the dead weight of the concrete swivel diagonal pull bridge is too large, which has exceeded the maximum bearing capacity of the existing spherical hinge. In order to continue to use the concrete swivel diagonal pull bridge scheme, it is necessary to optimize the design of the concrete swivel diagonal pull bridge scheme.
\end{abstract}

\section{Introduction}

With the rapid development of China's transportation industry, a large number of new passengers dedicated lines, intercity railways and urban expressways have been built. At the same time, along with the high-speed expansion of the main urban areas of some large and medium-sized cities, it is bound to lead to the emergence of more overpass railway Urban Bridges. Overpass railway bridge is an important project often encountered in highway construction. The selection of bridge construction technology has a great impact on the quality of bridge construction project. Reasonable structural design can ensure the safety performance of the whole project. And the railway that the bridge crosses generally carries a great traffic capacity, which can't be interrupted casually. Therefore, how to carry out the normal construction of the bridge without affecting the railway traffic is particularly important. Usually, the solution is to start with the design scheme of the bridge. The completion of urban bridge over railway will improve the coverage of urban road network, and the operation efficiency of the whole urban road network will also be improved, which will make an important contribution to the development of the city. At present, for the design of urban bridges over railway, the single tower concrete girder cable-stayed bridge constructed by horizontal rotation method is mostly considered from the perspective of reducing the impact on the existing railway operation under the bridge. This type of bridge has the characteristics of beautiful shape and flexible structure[1 $\sim 12]$.

\section{Methods}

Step1: On the premise of ensuring the feasibility, the project should also meet other requirements put forward by the owner as far as possible, strive to be beautiful in appearance, and arrange the bridge scheme on the premise of minimizing the impact on railway operation.

Step2: As the bridge is located at the side of small pile number, there is planned urban road, and there is planning station East Road on the side of large pile number. Therefore, it is considered to reserve a passage under the bridge side of the bridge.

Step3: Collecting and consulting the design scheme and construction technology of the existing bridge, combining with the project overview of the bridge, the process cases with reference value are selected. And collect the construction technology and experience of the cable-stayed bridge swivel, combined with the current development of the bridge swivel, and then determine the structure of the bridge to be used.

Step4: The bridge design scheme shall minimize the 
railway operation loss caused by the later operation and maintenance of the bridge, and shall not deteriorate the existing railway operation conditions.

Step5:According to the requirements of the railway department, the long-term development of the railway should be taken into account.

\section{Scheme comparison and selection}

\subsection{Recommended scheme}

The span of the bridge is $(128+388+128)$ meters steel mixed composite beam swivel cable-stayed bridge. In order to reduce the weight of swivel, the middle span of bridge is designed as steel box girder. In order to make the weight difference between the two ends of the spherical hinge as small as possible, the side span is prestressed concrete box girder. As a new type of structural bridge, hybrid girder cable-stayed bridge has significant advantages in stress and structural design. It has excellent performance in self weight and span ability. However, in the later operation of the bridge, a large amount of resources are needed for maintenance, and the maintenance requirements are high. Because the project spans several existing railways, it will bring certain safety risks to the railway operation when it is put into operation in the later stage and regular maintenance and coating are carried out.

\subsection{Trial design of bridge scheme 1}

Considering the needs of bridge operation and maintenance in the later stage of the bridge, the $(138+268$ +138 ) meters prestressed concrete box girder swivel cable-stayed bridge is proposed for the trial design of the bridge. Compared with the steel-concrete hybrid girder cable-stayed bridge, the self-weight of the concrete beam cable-stayed bridge will increase significantly. Therefore, the requirements of spherical joint will be greatly improved. However, the concrete box girder has obvious advantages in the later maintenance, and the driving experience is relatively good, the maintenance cost is low, and the overall cost is lower than the economic maintenance requirements.

\subsection{Trial design of bridge scheme 2}

Considering the factors of landscape design, the shape of bridge tower adopts H-type bridge tower. In scheme 2, $(128+388+128)$ meters steel-concrete composite girder is used to push the cable-stayed bridge. The main beam is a double side box structure. The side box is connected with the side box by a large cross beam. At the same time, a small beam is set between the large beams to increase its stability. The deck of main girder is made of precast concrete. Although the cost scheme of this scheme is lower, temporary piers need to be set between the lines in operation during the construction of the scheme, which will have a greater impact on the line operation. At the same time, the economy is general and the construction period is long.

After the comparison and selection of schemes, the author selects the first scheme of bridge for finite element modeling analysis.

\section{Trial design of bridge parameters}

\subsection{Grid Selection}

The main girder of the selected bridge is prestressed concrete box girder. The main girder section is $\mathrm{W}$-shaped web section, the top plate width is $45 \mathrm{~m}$, the floor width is $20 \mathrm{~m}$, and the box girder height at the center is $3.8 \mathrm{~m}$. In the standard section, the thickness of top plate is $30 \mathrm{~cm}$, the thickness of bottom plate is $35 \mathrm{~cm}$, the thickness of outer inclined web is $40 \mathrm{~cm}$, and the thickness of inner inclined web is $30 \mathrm{~cm}$. The main beam is provided with a diaphragm at the connection between the bridge tower and the beam end. The thickness of diaphragms at different joints is different, which is $12 \mathrm{~m}$ at the parent tower, $11 \mathrm{~m}$ at the connection between the sub tower and the main beam, and 2 meters at the beam end. The concrete grade of bridge is C55.

\subsection{Modeling and foundation design of main tower}

Single column pylon is recommended for this bridge. The shape of the upper tower adopts the traditional national musical instrument Sheng as the design idea. Through the evolution of its shape, combined with the characteristics of its own bridge tower structure. However, in order to simplify the modeling process, the inverted Y-shaped main tower is proposed. The inverted Y-shaped main tower can not only meet the design requirements of the main tower in the comparison scheme, but also meet the design requirements in terms of stress and stiffness, and can resist large bending moment. The tower height above the bridge deck is $68 \mathrm{~m}$, in which the vertical height of the left and right sides of the tower body is $50 \mathrm{~m}$. The anchorage zone of stay cable is set in the middle tower column section, and the central tower column adopts hollow section. The $3 \mathrm{~d}$ model of bridge tower is shown in Figure 1

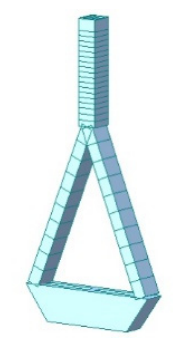

Fig.3.1 Finite element model of main tower

The left and right sides of the main tower body extend upward and meet the middle tower column. The vertical height of the tower body is $50 \mathrm{~m}$ and the height of the middle tower is $18 \mathrm{~m}$, all of which are hollow sections. 


\section{Self weight calculation of whole bridge model}

Midas civil is used to establish the model of main beam and bridge tower, and the self weight of the whole bridge model is roughly estimated. If the dead weight can be controlled within 60000 tons, it can be proved that the scheme is feasible in terms of swivel weight. At present, the domestic swivel tonnage has reached 46000 tons, and the swivel balance control of cable-stayed bridge structure is relatively mature. After a certain period of design and manufacturing, it can reach 60000 tons of bridge swivel.It can be seen from Figure 4 that the reaction force at the bottom of the bridge tower is $708712.3 \mathrm{kn}$, which can be converted into a mass of about 71000 tons, that is, when the bridge rotates, the weight of the spherical hinge is 71000 tons

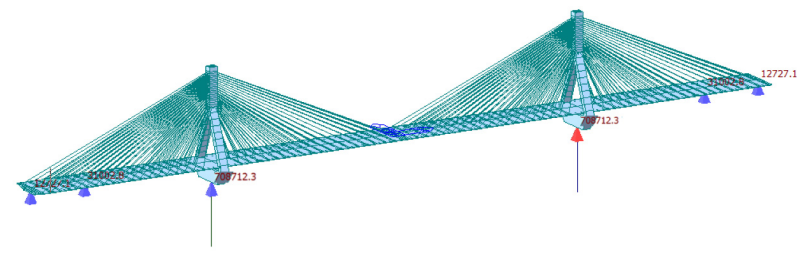

Fig.5.1 Calculation results of finite element model

\section{Development status of swivel ball joint}

The swivel hinge is located at the bottom of the pier and can be used to rotate. Swivel hinge plays an irreplaceable role in the swivel of the bridge. The self weight of the bridge basically acts on the swivel hinge. Therefore, the manufacture and bearing capacity of the swivel hinge should reach a high standard. There are also different structural forms of swivel hinge. We mainly classify it into two types: spherical hinge with shape similar to spherical surface and plane hinge whose action surface is plane. Because the materials used for making swivel hinges are different, we can roughly divide them into two categories according to different raw materials. The raw material is the swivel hinge of concrete, so we call it concrete hinge. If the raw material is steel hinge, we call it steel hinge. When we choose the swivel hinge, we should design the swivel hinge according to the needs of the bridge. Each swivel hinge should be made according to the swivel bridge, so as to make the selected swivel hinge suitable for the actual needs of the project as far as possible, so as to ensure the stable and safe rotation of the bridge during the swivel process. Because of the large span and self weight of the swivel bridge, the spherical hinge has the best bearing effect. Therefore, this paper focuses on the development status of the spherical hinge.

\subsection{Concrete Swivel Ball Joint}

In the swivel ball joint, the ball joint can be classified according to different manufacturing materials. The spherical hinge made of concrete is called concrete hinge. When the raw material belongs to steel, it is steel ball hinge.Among them, in order to ensure the bearing capacity of the spherical hinge, the concrete spherical hinge is generally made of high-grade concrete, and the strength grade of concrete is generally above $\mathrm{C} 50$. There are some differences between concrete spherical hinge and steel spherical hinge in structural design. The concrete spherical hinge is generally divided into two parts: the upper and the lower. The upper ball gap is called "upper grinding plate". The upper part of the ball gap and the lower part of the ball need to fit enough to meet the force and rotation requirements. In order to make them meet the rotation requirements, we usually scrape off the surface of the ball gap to make a perfect fit. Before pouring and setting with concrete, the grinding disc and grinding center should be checked manually to ensure that the contact surface can run in well. When rotating, the friction force during rotation should be minimized to make the rotation process smoother. First of all, it is not necessary to obtain the advantages of concrete ball in terms of material selection and technology. Especially in some places where the working condition is not good and some large-scale instruments cannot reach, the concrete spherical hinge can reach the construction site by ordinary methods. In the existing swivel bridge, it is very common to use the concrete ball joint in the swivel bridge. Therefore, according to these projects, the technical parameters of the concrete spherical hinge also have a certain standard. The static friction coefficient of concrete spherical hinge is less than 0.05 , and the dynamic friction coefficient is less than 0.03 . Among these existing swivel bridges, the self-weight of swivel bridges has reached 9000 tons. The weight of the swivel is very different from that of this project, so the use of concrete spherical hinge is not considered.

\subsection{Steel ball joint}

The steel ball hinge is also composed of two parts, which is different from the concrete ball hinge. The upper and lower parts of the steel ball hinge are not the shape of solid ball gap, but are made of thick steel plate. After the steel plate is pressed into a spherical surface on the special equipment, the upper and lower spherical hinge is connected through the steel shaft, and the circular c2f4 (tetrafluoroethylene) mushroom head and c2f4 sliding blade are arranged at the joint of the spherical joint. Steel itself has great strength, so the bearing capacity is obviously better than the concrete hinge. Therefore, in the long-span swivel bridge, the steel ball hinge has been widely used. At present, when steel ball hinge is used to rotate the bridge, the bearing capacity has reached about 50000 tons. In theory, it is possible to design the swivel of the bridge through the design of the spherical joint and the overall optimization design of the bridge, so the construction risk is relatively small.

\section{7 conclusion}

The calculation results show that the weight of the bridge in scheme I has greatly exceeded the weight of existing swivel bridges in China. Because of the simple weight estimation of the model, the boundary conditions are also applied to the end of the bridge, that is, the fulcrum of the bridge beam end also shares part of the reaction force. Therefore, in the actual project, the weight of the spherical 
hinge is greater than 70000 tons. If we want to continue to consider the use of prestressed concrete box girder, it is necessary to optimize the design of the girder section and the size of the bridge tower to reduce the weight of the structure. At the same time, the ball joint, the core part of the swivel structure, also needs to have high quality requirements.

\section{Acknowledgements}

Thanks for the support of the fund: Research project of Yunnan Provincial Department of Transportation Yun Jiao Science and Education [2018]No.43

\section{References}

1. Qin shaozong. Research on monitoring technology for Swivel Construction of cable stayed bridge across railway lines [D]. Shijiazhuang Railway University, 2019.

2. Zhang Li. Study on mechanical properties of composite tower and steel-concrete composite section of main beam of hybrid girder cable-stayed bridge [D]. Hunan University, 2019.

3. Han Feifei. Structural system research and parameter analysis of partial cable-stayed bridges [D]. Hefei University of technology, 2019.

4. Wang Xuxu. Research on key design issues of Large Span Composite Girder single tower swivel cable stayed bridge [D]. Tianjin University, 2018.

5. Yao Youlin. Study on technical and economic characteristics of girder types for cable stayed bridges with different spans [D]. Hunan University, 2017.

6. Li Haijun. Design and construction control analysis of prestressed concrete single cable plane cable stayed bridge [D]. Shijiazhuang Railway University, 2016.

7. Tang zhunzun, Tan Ke. Discussion on comparison and selection of preliminary design schemes for a super large bridge $[\mathrm{J}]$. China high tech enterprises, 2014 (19): 31-32.

8. Dong Zhuangzhuang. Study on Optimization of construction scheme of stay cable and main girder steel bundle of horizontal rotation cable-stayed bridge [D]. Chongqing Jiaotong University, 2013.

9. Lv yaoxiu. Comparison and selection of cable stayed bridge design schemes [J]. Shanxi architecture, 2010,36 (02): 322-323. [2] Chen Yifei. Analysis, evaluation and identification of cable bridge structure based on long-term monitoring [D]. Dalian Maritime University, 2018.

10. Cheng W U Study of Cable and Pylon Structure Types of Cable-stayed Bridge using Swivel Construction with the Characteristics of Broad Bridge Deck and Steel Girder[J]. Transportation Science \& Technology, 2017.

11. Quan-Sheng S, Shi-Jie W, Yong-Cun S, et al. Static Load Test and Research on Cable-Stayed Bridge with Horizontal Swivel,Single Tower and Single Cable
Plane[J]. Highway, 2008.

12. Luo R D, Wang H L, Hu J H . Deformation and Stress Analysis of an Asymmetric Single Tower CableStayed Bridge on High Speed Railway in Swiveling Process[J]. Advanced Materials Research, 2015, 1079-1080:359-363. 